\title{
Humour and other catastrophes: dealing with the translation of mixed-genre TV Series
}

\author{
Chiara Bucaria \\ University of Bologna at Forlì
}

Starting from a trend observed in the Italian dubbing of US series "Six Feet Under" (Bucaria 2005; Bucaria forthcoming) involving the deletion or toning down of most instances of potentially disturbing elements, this paper will take into consideration examples from three US TV series ("House MD," "Nip/Tuck" and "Six Feet Under") dubbed into Italian and presenting a mixture of drama and comedy, in an attempt to analyze the degree of manipulation or adaptation that they underwent in terms of the linguistic representation of clashing genres. With particular reference to the rendering of humorous comments produced in unexpected contexts, the analysis shows considerable manipulation in the translated versions and a consequent decrease in the humorous content of the target texts.

\section{Manipulating Humour in AVT}

Humour and censorship are historically two closely interconnected issues, in view of the fact that the former often upsets conventional and universally recognised social and moral rules, whereas the latter tends to maintain them or at least to abide by them. Next to literature, the media is perhaps one of the fields in which censorial intervention on humour has been most active. From Monty Python and South Park to Lenny Bruce and Borat, TV and cinema have always been some of the preferred targets for religious, parental and political disdain. Consequently, the history of motion pictures and TV abounds with anecdotes concerning censorial intervention in various historic periods and geo-cultural contexts (e.g. Mathews 1994; Grieveson 2004), due to a number of different reasons.

Furthermore, because of the massive importation of audiovisual products, mainly from English speaking countries, the issue of censorship has also become closely interlinked with audiovisual translation (AVT). However, although studies about translation and censorship have rightly addressed the issue of its interdependence with political regimes (e.g. Rundle 1999, 2000; Sturge 1999, 2002; Vandaele 2002), less attention in the academic discourse on translation has been devoted to the contemporary and probably subtler forms of text manipulation that are still presently applied, especially in the sphere of $\mathrm{AVT}^{1}$. In fact, censorial intervention is still commonly found in Italy and other countries. As a typical example among English-speaking countries, in the US different versions of the same films are edited depending on whether they will be viewed at the cinema, 
on TV or on planes ${ }^{2}$. In Italy, where the large majority of TV products is translated from American English (Bucaria \& Chiaro forthcoming) and adapted for the audience by means of dubbing, this is often done more subtly, usually without even informing the viewer that substantial changes have been made. This is obviously possible because, unlike with subtitling, when watching a dubbed product the audience has no simultaneous access to the original version and has no way of noticing if the translation is only partially accurate or if it has been conveniently modified ${ }^{3}$.

In the majority of cases, what viewers can or cannot watch or hear on TV is still decided by some higher authority. Often the commissioners of the translations have the power to decide what can be said and what should be left out, and their judgement is not only based on network policies or national regulations, but also on their precise expectations about the target audience (e.g. age and level of education) or the time slot in which the programme will be aired. Some commissioners also provide the translators/adaptors with lists of words that are not allowed in dubbed products and of references to concepts or ideas that should be avoided (personal communication). However, it still remains difficult to talk about censorial intervention without knowing the specifics of each translation process, since other factors linked to the human element such as selfcensorship, simple oversights or even translator incompetence might also be at stake. Therefore, the more generic term 'text manipulation' will be preferred in the rest of the paper.

Examples of arbitrarily adapted shows on Italian TV are numerous. They go from The Nanny - La Tata and Roseanne - Pappa e Ciccia to the more recent Buffy - The Vampire Slayer (Bianchi forthcoming), Six Feet Under and Will \& Grace, to mention just the most clamorous cases. According to a point of view that is sadly popular even among some AVT professionals and researchers, the manipulation of referential and verbal humour is just a necessary evil inherent in the process of localization, since translating for a different audience obviously implies some changes and choices that are reputed more "suitable" for the target viewers/readers, etc. Although it is undeniable that a certain amount of adaptation is desirable, especially in order to facilitate foreign viewers' comprehension, AVT cannot abstract itself from considerations pertaining to the respect for the source language text on the one hand and for the target audience on the other.

Although academic studies concerning the complex mechanisms involved in AVT have occasionally touched upon the translation of humour and its manipulation (e.g. Vandaele 2002; Bucaria 2005 and forthcoming; Chiaro 2006), not many seem to have tackled the issue in filmic texts that are not comic per se but that present a mixture of drama and comedy that has recently become quite popular in imported TV productions. The aim of the present paper is therefore that of focusing on the specific aspect of the manipulation of humorous contents by taking into consideration three different TV series and their respective Italian dubbed versions: House MD 
(HMD), Nip/Tuck (NT) and Six Feet Under (SFU) ${ }^{4}$. These series were chosen as some of the most controversial products that have made their appearance on Italian TV in the last few years, because of both the language they employ and the potentially disturbing situations they portray. These series are also meant to be somewhat representative of a trend in recent TV shows, which more and more often tend to elude genre classifications and to present characteristics of drama and comedy together. Another reason for selecting this kind of audiovisual products is that editing is here obviously easier than, for example, in sitcoms, where punch lines are always followed by a laugh track, which would make complete deletion of a funny remark impossible unless the audience's laughter is also digitally omitted. Based on the results of a case study on Six Feet Under (Bucaria 2005 and forthcoming) noticing the systematic toning down of the language and, consequently, of the comic content through dubbing, examples from the first seasons of the above-mentioned series will be analyzed in order to show how significant text manipulation is consistently found in the dubbed versions of the programmes in question. More specifically, attention will be paid to the ways in which humour involving the use of strong language and of potentially disturbing elements was rendered through the filter of dubbing.

\section{The analysis}

The three series chosen as material for the analysis all have in common aspects such as dark humour ${ }^{5}$ and sexual humour, as well as references to the potentially disturbing depiction of some aspects of life portrayed in their settings and storylines. A quick look at a general description of each of these shows will probably help contextualize the next paragraphs better.

House MD, also known as House, revolves around the main character, Dr Gregory House (Hugh Laurie), a misanthropic but extremely brilliant doctor specialized in infectious diseases, and his team of young specialists, Dr Allison Cameron (Jennifer Morrison), Dr Eric Foreman (Omar Epps) and Dr Robert Chase (Jesse Spencer). Other recurring characters are Dr James Wilson (Robert Sean Leonard), who is also House's friend and partner in crime on many occasions, and Dr Lisa Cuddy (Lisa Eldestein), the hospital administrator whom we often see trying to cope with the hard task of having House behave like a real doctor. Set in the fictitious New Jersey Princeton-Plainsboro Teaching Hospital, each episode analyzes a case for which the diagnosis results particularly problematic, until one of the doctors' brilliant intuitions solves the case. The series has often been defined as a mixture of crime fiction and medical drama, because of its storylines typically involving a process similar to the one adopted in solving a crime. Dr House's unconventional and slightly antisocial personality and behaviour, which lead him to distrust people, and especially patients, a priori, make him stand out maybe even more than the fact that he is forced to walk with the help of a cane as a consequence of an infarction in his 
thigh muscles. HMD was first aired by American TV channel FOX in 2004 and at the moment of writing is still showing in the US. The series was first aired in Italy in 2005 , on the national TV channel Italia 1, during the primetime slot. The Italian DVD version of the first season used for the analysis indicates the series as suitable for everybody ${ }^{6}$.

Nip/Tuck's (NT) central characters are two talented plastic surgeons, Christian Troy (Julian McMahon) and Sean McNamara (Dylan Walsh), who own a successful practice in Miami, Florida, run with the help of faithful anesthesiologist Liz (Roma Maffia). Christian and Sean have been good friends since college, but they lead very different lives. While Christian is single and always in search of the next sexual conquest, Sean is a family man, married to Julia (Joely Richardson) and father of Matt (John Hensley) and Annie (Kelsey Batelaan), who seems to be dissatisfied with his routine existence. Each episode revolves around one of the cases that Christian and Sean accept for surgery at their practice and around the consequences that these cases have on their personal lives. One of the main characteristics of the show is its extremely strong visual impact, such as in the case of surgeries that are always extensively shown in detail on camera and of Christian's frequent sexual encounters. NT has been aired in the US on the FX channel since 2003. Italia 1 has been scheduling the dubbed version of the show since 2004 during the late night time slot. Surprisingly, the series' DVD is labelled as suitable for everybody.

Six Feet Under (SFU) tells the story of a family working in the funeral business, the Fishers, who have been recently bereaved of the head of the family, Nathaniel (Richard Jenkins), killed in a car crash. Wife Ruth (Frances Conroy) and children Nate (Peter Krause), David (Michael C. Hall) and Claire (Lauren Ambrose) are followed in their coming to terms with the recent loss and with its implications for their lives. Despite the fact that death is such a pre-eminent theme in the series, it is not the only potentially disturbing one. David is a closeted homosexual, who at the beginning of the series has a relationship with Keith (Mathew St. Patrick), an AfricanAmerican police officer. Teenage Claire is experimenting with drugs and has quite a rebellious personality. Nate's love interest, Brenda (Rachel Griffiths) develops an addiction for dangerously promiscuous sexual behaviour. Federico (Freddy Rodriguez), the Fishers' embalmer, acts in many cases as the comic relief, with his nonchalant attitude towards his work and the funeral business in general. Nathaniel's ghost's bizarre appearances and the dreamlike character of some scenes also add to the dark and surreal tone of the series. SFU first appeared in 2001 on HBO, where it was aired until its final season in 2005. The series was first broadcast in Italy in March 2004 on the terrestrial channel Italia 1, where the first two seasons were shown late at night, two episodes at a time, once a week. The Italian DVD version of the first season used for the analysis indicates the series as restricted for people under 14. 
The analysis of the first seasons of HMD, NT and SFU identified two categories of elements in which the language and content respectively might result in some kind of intervention on the part of translators or the commissioners:

- $\quad$ swearwords and other strong expressions;

- $\quad$ potentially disturbing elements.

By means of specific examples from the three series, the following paragraphs will comment on the strategies used in the Italian dubbed version whenever such elements are encountered.

\subsection{Swearwords and strong expressions}

In this section I will discuss examples containing not only swearwords that are generally considered as offensive, for instance the ones related to the sexual/scatological sphere (Chiaro this volume) and to blasphemy, but also cases of what are usually looked at as milder insults, expletives and euphemisms, since on some occasions these were the object of manipulation as well. ${ }^{7}$

However, we will start by looking at swearwords in the more widespread meaning of the term, e.g. different variations of fuck and fucking, together with several examples of shit, bastard, asshole and some blasphemy, such as goddamit, hell, Christ, Jesus, etc. A concrete count of swearwords used in the pilot episode of each series in the English and in the Italian versions will offer a good starting point for a quantitative analysis.

Table 1: Number of swearwords in the English and Italian versions.

House M.D.

Nip/Tuck

Six Feet Under

$$
\text { English }
$$

6

\section{Italian}

1

9

As Table 1 shows, the least amount of swearwords is found in the pilot episode of HMD, a datum that can intuitively be considered as a general indicator for the whole series as well. Also, the series stands out for the use of relatively mild swearwords and minor epithets if compared to the other two series, in which stronger language is usually found. On the other hand, SFU presents the highest number of swearwords and, proportionally, the most severe intervention in terms of deletion, with only 9 out of 43 items left in the Italian version. NT ranks as the most "faithful" rendering in the dubbed version, where 27 out of 36 examples of cursing are still present in Italian. 
In terms of general trends present in the three different series, four strategies are consistently found when coping with swearwords and other examples of strong language:

- $\quad$ complete omission;

- weakening;

- close rendering;

- $\quad$ increased effect.

It is easy to see how in the cases in which the swearwords are either completely omitted or toned down, the lack of verbal impact often causes not only a mismatch in the representation of the characters but also a decrease in the comic effect. The following paragraphs will comment on examples in which the humorous content of the English language lines is considerably reduced in the Italian version, especially because of swearword omission and weakening. All the examples include, in this order, the English original, the dubbed Italian version and the English literal back translation.

Complete omission

In examples in which this strategy was applied, the disturbing element has been completely deleted and often substituted with a totally neutral comment.

Example 1: from SFU, episode 3.

ST That guy's into some crazy shit. Now, either you can tell me where you put the foot or you're gonna be dealing with that crazy-ass motherfucker.

TT $\grave{E}$ in servizio da 72 ore filate. Quindi ora o mi spieghi bene che cosa hai combinato o scopriremo gli effetti della sua carenza di sonno.

BT [He's been on a 72 hour shift. So now you either tell me what you've done or we'll find out about the effects of his lack of sleep.]

Above is one of the many examples from SFU, episode 3, in which strong language is used. In episode 3, "The Foot," Keith and David are trying to recover a missing human foot that Claire has stolen from a body in the funeral home in order to teach her boyfriend Gabe a lesson. Keith is trying to get some information about the location of the missing foot from an uncooperative Gabe, while David is sitting in the police car. He is looking out towards Gabe with an upset expression on his face. The whole dialogue is an attempt to scare Gabe, in a sort of "good cop/bad cop" routine.

As can be seen from the back translation, both the references to "crazy shit" and "crazy-ass motherfucker" are carefully omitted and replaced by a comment on the "bad cop"'s lack of sleep. Of course, for the viewers who 
already know David's very poised and passive aggressive nature there is nothing more ridiculous than thinking of him as "a crazy-ass motherfucker" who is also into "some crazy shit." The humorous effect is thus clearly diluted by the omission of the swearwords, and maybe just hinted at immediately afterwards by means of David's facial expression and awkward body language.

Example 2 from NT's Pilot is taken from a scene in which Christian and Sean are discussing the possibility of accepting as a client a porn star who needs plastic surgery before shooting a movie. Sean voices his unease at this prospect, while Christian, on the other hand, accuses him of being a prude and stresses the importance of this client for their practice's finances.

Example 2: from NT, pilot episode.

A tight ass may make money for her [the porn star] but not for us.

TT Non mi interessa da dove provengono i soldi, basta che ci siano.

BT [I don't care where the money comes from, as long as it's there.]

Humour in the source version relies obviously on the double meaning of the phrase "tight ass," referring both to an uptight, overcautious person and to a well-shaped and attractive rear end. The Italian translation chooses to delete not only the supposedly offensive reference but also, as a consequence, the cleverly phrased line and prefers to paraphrase Christian's meaning with a very neutral and business-like comment.

Another example from HMD, pilot episode, in which the dubbed version paraphrases the English line is found in example 3. Dr Cameron is confronting Dr House on the real reason why she was chosen as a member of his team. House replies that he selected her over more qualified candidates because her beauty did not stop her from working really hard for her goals instead of settling for an easier life as a model or as the wife of a rich man.

Example 3: from HMD, pilot episode.

ST You worked your stunning little ass off.

TT Tu invece hai preferito lavorare come una dannata.

BT [You, on the other hand, preferred to work like a person who's been damned.]

To the extremely informal expression "to work one's ass off," the Italian version prefers the equally informal "lavorare come un dannato," roughly meaning to work like a dog. However, the absence of the swearword in the translation does not do justice to House's characteristically unusual conversational style, in which he often catches his interlocutors unprepared with 
startling comments or unconventional expressions. Also, the pragmatic impact of the word "dannato" should not be mistakenly likened to that of damned in English, since the Italian carries much weaker connotations.

Weakening

Cases characterized by a weakening strategy typically present a disturbing element that has been rendered with a diluted, harmless equivalent in the dubbed version. Examples 4, 5 and 6 below are typical examples.

Example 4: from NT, pilot episode.

ST Ass implants: what will they think of next?

TT Protesi alle natiche. Cos'altro si inventeranno?

BT [Buttock implants. What will they invent next?]

Example 5: from HMD, pilot episode.

ST (...) you rightly think I should fire him, but I can't, even if it cost me your money. The son of a bitch is the best doctor we have.

TT (...) immagino che tu sia qui per chiedere il licenziamento di House. Ma non posso farlo. Anche se perderò i tuoi soldi. Quel misogino è il miglior medico che abbiamo.

BT [(...) I guess you're here to ask that House be fired. But I can't do that. Even if I'll lose your money. That misogynist is the best doctor we have.]

Example 6: from SFU, episode 3.

ST Greedy little Nazi fuck.

TT Che schifoso avido nazista.

BT [What a filthy greedy Nazi.]

Example 6 is taken from one of the first scenes in NT's pilot episode, in which Christian and Sean are performing buttock augmentation surgery on a female patient. Liz, the anesthesiologist, is assisting them and, in line with her straightforward, outspoken personality, she makes the light-hearted comment above. The downplaying of the word "ass" in the Italian translation by means of the word "natiche" (buttocks) certainly neutralizes the comic dimension of Liz's remark and brings it back to a relatively dull comment uttered by a plastic surgery professional about new medical advances. The expletive "son of a bitch" pronounced by Dr Cuddy in example 5 is also toned down in the dubbed version, where Dr. House simply becomes a "misogino." In this case, which is also one of the rare examples of swearwords in the pilot episode, the original expression was probably diluted because such strong language used by the hospital administrator to refer to a colleague frustrates the viewers' expectations of what a similar 
working relationship should be like. Of course, the humorous content in the English version relies specifically on such reversal of expectations.

Whereas in the two previous examples we noticed a one-to-one lexical substitution, in example 6 the manipulation extends to the phrase level, with the expletive "fuck" being omitted and the colloquial, although not vulgar, dimension of the comment shifted to the adjective "schifoso" (filthy, repulsive). The phrase, pronounced by Nathaniel Fisher's ghost and addressed to the head of a multinational funeral company aiming to buy the Fisher's family business, clearly loses its edge.

Close rendering

Despite the presence of extensive swearword omission or weakening, it is to be noted that on a number of occasions the target language version manages to convey the humorous content linked to the use of swearwords and strong language. Examples 7 and 8 are cases in point.

Example 7: from SFU, episode 3.

ST That guy just cruised you. Bitch.

TT Quello ti ha guardato? Puttanella.

BT [Did that guy look at you? Little bitch...]

Example 8: from SFU, episode 3.

ST

C: You saved my ass again.

L: And hers.

TT C: Mi hai di nuovo salvato il culo.

L: Non solo il suo.

BT $\quad[$ C: You saved my ass again.

L: Not only his.]

In both cases, we can observe a close rendering of "bitch" and "ass," respectively rendered as "puttanella" and "culo." The first example clearly conveys Keith's indignant comment at David's being blatantly cruised by another man in his presence. Example 8, on the other hand, successfully employs the Italian expression "salvare il culo," which is analogous to the English version. It is worth noting that the second exchange takes place in the same scene commented on in example 4 above, in which Sean realizes that Christian has put the buttock implants in upside down. Christian replies with the line seen in example 8 and Liz, as often happens, adds a humorous comment, in this case about the operation's success. Surprisingly, unlike example 4, the word "ass" was transposed with its more obvious and stylistically appropriate equivalent "culo." This choice might perhaps be due to the existence of a readily available and almost identical Italian expression ("salvare il culo") and, more importantly, to the interaction of the verbal and the visual codes (a close-up shot of the patient's buttocks) that made 
this strategy somewhat inevitable. In example 4, on the other hand, the absence of idiomatic expressions made the substitution with a less disturbing element less problematic on a practical level.

\section{Increased effect}

Albeit rarely, some cases occur in which the pragmatic intensity of swearwords has been increased in the target version. Whether this was due to misinterpretation or to conscious compensatory strategies on the part of the translators/adaptors, is not easy to assess. Two illustrative examples are reported below (examples 9 and 10).

Example 9: from NT, pilot episode.

ST I'm not gonna have my entire life destroyed just because you two screwed up!

TT Non avete il diritto di rovinare la mia vita professionale solo perché siete due teste di cazzo!

BT [You don't have the right to ruin my professional life just because you two are dick heads!]

Example 10: from HMD, episode 2.

ST Oh, crap.

TT Oh, merda.

BT [Oh, shit.]

As can be seen from the back translation, strangely enough, in some of the rare cases in which euphemisms were used in the English version more explicit language is preferred in the target language. Although a compensatory strategy might be hypothesized here in order partially to make up for other obscenities deleted elsewhere in the episode, we cannot help but noticing how in the case of swearwords this could be actually a double-edged weapon. In particular, one of the side effects might be the pitfall of attributing a compensatory swearword to characters that would not normally resort to this kind of language (as is the case in example 11 pronounced by Dr House) or of grossly exaggerating the contextual intensity of the insult (as in example 10 pronounced by an albeit enraged Liz).

After having identified the general strategies adopted for the transposition of swearwords and other examples of strong language, it will be worth spending a few words on what kind of choices are usually preferred in each of the series taken into consideration, in an attempt to identify possible common patterns. Table 1 has already shown in part how very precise choices have been made in the three separate series, presumably as a specific "bad language" policy on the part of the commissioners. 
In particular, SFU stands out for its almost total deletion or weakening of swearwords, except in cases in which the use of bad language is requested by other characters' reactions, as in the following exchange between Nate and Ruth at Nathaniel Fisher's wake.

Example 11: from SFU, pilot episode.

ST N: David, she's grief stricken, ok? Fuck propriety!

R: We don't say that word!

TT N: David, è uno sfogo. Chiudi quella bocca di merda!

$R$ : Non pronunciare quella parola!

BT [N: David, it's an outburst. Shut your shitty mouth!

R: Don't say that word!]

The Italian version of NT generally tends to preserve swearwords, although, as we have shown, with some editing and weakening. Also, in a number of cases, the translators/adaptors adopted what are clearly to be considered as compensatory solutions, as shown in example 12.

Example 12: from NT, pilot episode.

ST I guess he was showering in gym class and shit and some tough guys were laughing at him...

TT Credo stesse facendo la doccia, degli stronzetti cominciano a ridere...

BT [I think he was taking a shower, some little assholes started to laugh...]

In the example above, in which Christian is telling Sean about Matt's problems with some bullies at school, the rendering of the word "shit" in its non referential meaning of "stuff," "thing," etc. would have been problematic in Italian. However, instead of depurating the sentence altogether, an attempt was made to shift the vulgar content to the immediately following items by inserting the word "stronzetti." This strategy is found in several other examples and is probably symptomatic of the fact that the avoidance of swearwords in the dubbed version was not considered a priority.

As seen in Table 1, despite their low quantity of swearwords the dialogues in HMD also tend to be edited for obscenity in Italian, either by complete omission or by weakening. However, what is most surprising is the choice to tone down not only vulgar language that is generally perceived as such, but also minor epithets such as moron, idiot and jerk. The example in table 14 is an emblematic case. 
Example 13: from HMD, pilot episode.

ST You're orange, you moron!

TT Non lo vede che è tutto arancione?

BT [Can't you see you're all orange?]

The complete deletion of the word "moron" in the Italian version, for which many alternatives would actually have been possible (e.g. cretino, deficiente, idiota, etc.), is probably due to the lack of correspondence between Dr House's attitude and language and the way "normal" doctors treat their patients, that is ideally with respectful tact. In other words, Dr House's verbal bluntness might be a disturbing factor in that it frustrates the viewers' expectations or, more simply, because it is unbecoming for a doctor.

This and other similar examples show how in some cases dialogues were manipulated not because of the language itself but because of the unsettling underlying concepts that they convey, i.e. in this case socially and professionally questionable behaviour. This last observation attests to the interconnection of the two categories of analysis we have indentified and nicely leads us into a discussion on the translation of some of the potentially disturbing elements in these series.

\subsection{Potentially disturbing elements}

As already mentioned above, all the three series taken into consideration here deal with topics that might be on some level potentially disturbing for viewers. These typically include references to sexually explicit situations, homosexuality, death, drug abuse and all kinds of politically incorrect situations. Examples 14 and 15 below both refer to the (homo)sexual sphere.

Example 14: from NT, episode 9.

ST I'm sorry, they don't make a lipstick shade called bull dyke.

TT Non hanno ancora fatto un rossetto per le lesbiche mascoline.

BT [They haven't created a lipstick for masculine lesbians yet.]

Example 15: from SFU, episode 3.

ST What, like big, black sex cop?

TT Il poliziotto nero brutto e cattivo?

BT [The bad and ugly black cop?]

In the scene from which example 14 is taken, Liz and Sofia, a transsexual man she has become friends with, are having a "girls' night." Sofia offers to make Liz up in order to give her a younger look but when the woman sees the result she is not satisfied and comments that this look makes her look 
straight. At this point Sofia light-heartedly offers the humorous line in example 14. As can be seen from the back translation, the phrase "bull dyke" has been paraphrased with "lesbiche mascoline," which, albeit correct in meaning, obviously does not convey the colloquial and very informal character of the slangish English counterpart and, consequently, the clear humorous undertone of the remark. To be fair, however, it should be noted that the rendering that was chosen in Italian might be the only possible linguistic solution offered in a cultural context in which homosexuality is not only still considered a taboo, but also lacks the established and generally widely known referential vocabulary that is found in the Anglo-American culture. The translation of the example in table 16 also implicitly tones down a reference to sex. In this scene Claire is talking to Keith, her brother David's boyfriend, about the reasons why he likes him. One of the traits that he appreciates is David's ability to see him differently from guys who are only turned on by his macho appearance. Although this aspect is not clearly stated in the dialogues, Keith's looks remind us of the homosexual topos of the macho cop, made popular in the collective imaginary by the pop band The Village People. This implicit homosexual reference hinted at in Claire's line is left to the Italian viewers' inferential ability.

References to illegal drugs are also occasionally found.

Example 16: from SFU, episode 3.

ST N: And I suppose you were into the really hard core punk stuff.

B: Kind of. But I think it was just the heroin talking.

TT N: Io credevo ci fossi nata nel genere punk hard core.

B: Una specie. Direi che sono una figlia illegittima.

BT $\quad[\mathrm{N}$ : I thought you were born in the hard core punk genre.

B: Kind of. I'd say I'm an illegitimate child.]

In example 16, Brenda and Nate, who have known each other only for a short period of time, are jokingly talking about musical tastes and childhood memories. Out of the blue, the woman throws in the reference to heroin use in her younger days, and Nate, who does not know her well enough to know if she is joking or not, is visibly taken aback. The whole exchange is modified in the Italian version, with the reference to hard drugs changed to one about Brenda's illegitimate birth. The idea of being born out of wedlock is of course not, not even in Italy, powerful enough to justify Nate's troubled reaction.

Given the settings and themes of the three series in questions, references to death abound in these shows. Furthermore, given the unconventional character of these audiovisual products, it is not surprising that said references to death often contain veins of black or macabre humour. Although this could be considered as a general trend in HMD, NT and SFU alike, the latter show seems to reach the peak of potentially 
disturbing death-related elements. In fact, as previous research on the Italian versions of this series has shown (Bucaria 2005, forthcoming), SFU's balanced mix between drama and offbeat comedy is likely to yield mixed results in terms of audience appreciation. Numerous examples of what would commonly be referred to as black humour are present in the pilot episode of the series, among which, for instance, four fake commercials for funeral products advertising items that are seen immediately afterwards in the episode: a luxury funeral coach, a selfsealing moulding putty, an embalming fluid and an earth dispenser similar to a salt shaker. Although these commercials are only present in the pilot episode, black humour is consistently found throughout the series and almost always equally consistently toned down in the Italian dubbed version. Example 17 is a typical example.

Example 17: from SFU, episode 3.

ST Wife: Is he all put together?

David: Oh, he's a hundred percent there.

TT Wife: E come procede il lavoro?

David: Oh, resterà a bocca aperta, stia certa.

BT [Wife: How's the work going?

David: Oh, you'll be left with your mouth open.]

In episode 3 already mentioned above, the family of a man who died after falling in a dough mixer that had accidentally been switched on turns to Fisher\&Sons requiring that the body be put together perfectly for an open casket funeral. Nate and David accept the client but their sister Claire subsequently steals the man's foot that goes missing. In this scene the two brothers are awkwardly trying to reassure the man's wife that everything will be ready and in order for the wake. Although the Italian version is successful in keeping a slightly humorous equivalent of the English original, it is clear how the absence of references to all the different pieces in which the body has been cut does not convey the source language text's macabre humour.

Dr House's blunt humour is often expressed in politically incorrect ways. In example 18 we have an example of self-addressed humour.

Example 18: from HMD, pilot episode.

ST People used to have more respect for cripples you know!

TT Una volta c'era più rispetto per gli handicappati.

BT [There used to be more respect for disabled people.]

The substitution of the word "cripples" with the more politically correct "handicappati," is probably indicative of a similar trend as the one noticed in table 14 above, where it was hypothesized that the manipulation of the 
target text was due to reasons linked to audience expectations. The implications discussed for that line about humour loss are also clearly applicable to this case. It is to be noted, however, that a closer rendering of "cripple" in Italian (zoppo) was indeed used in other episodes (see for example the Pilot), although in that case the comment was not supposed to be humorous. This might be further evidence that the problem is not with the word itself but with its use in a humorous context.

One case in which intonation and not translation is responsible for a change in the humorous delivery of a line is found in example 19 where Dr Cuddy is comparing House's prescription of treatments to patients to the methods used by Nazi doctors.

Example 19: from HMD, pilot episode.

ST You're comparing me to a Nazi? Nice.

TT Mi paragoni ad un nazista? Carina.

As in many examples quoted above, the funniness of the comment lies in the fact that it subverts normal expectations: being compared to a Nazi is not usually considered a desirable thing, whereas House is genuinely impressed at the cleverness of Cuddy's comment. The Italian version reflects these normal expectations, since the ironic intonation with which the last word is delivered suggests that she is actually being rude and "not nice." This shows how poor signalling of irony, possibly on the part of one of the professionals involved in the dubbing process, creates manipulation and usually toning down of the humorous content. In this particular case the final version might have been the result of intervention in the dubbing studio itself, where, with very little or no knowledge of the source language, arbitrary changes are frequently made.

A final note on the variety of potentially disturbing elements affected by Italian dubbing should perhaps be devoted to observations on the issue of religion. Although no examples were found in which the Italian dubbing tried to omit or even to conceal comments that might be considered as disrespectful, HMD fan websites ${ }^{8}$ report at least two cases in which scenes were cut from the version of episode 5 ("Damned if you do") aired on Italian TV. One contains a comment on the Catholic Church's manipulation of young boys' will by means of the fear of God, whereas in the other one Dr House insinuates that a nun is committing one of the capital sins by having lustful thoughts about him. While these scenes were edited out of the TV version, no sign of manipulation is present on other occasions in the same episode where, as in example 20 below, strong comments are made not on the mere behaviour of members of the Catholic Church but on the very dogmas on which it is based. 
Example 20: from HMD, episode 5.

ST Nun: I need to talk with you, Dr. House. Sister Augustine believes in things that aren't real.

House: I thought that was a job requirement for you people.

TT Nun: Devo parlare con lei, Dottor House. Suor Augustine crede in cose che non sono reali.

House: Credevo che fosse un requisito di voi suore.

BT [Nun: I have to talk to you, Dr House. Suor Augustine crede in cose che non sono reali.

House: I thought that was a requisite for you nuns.]

One might then wonder what the criteria are for the omission or weakening of potentially disturbing elements and, once again, who decides what viewers will be offended or shocked by.

\section{Conclusions}

The present paper on the Italian transposition of swearwords and other potentially disturbing contents in the three controversial TV series House MD, Nip/Tuck and Six Feet Under showed generalized dialogue manipulation in the presence of such elements. In particular, as far as the rendering of swearwords and strong language is concerned, four main strategies were found: complete omission, weakening, close rendering and increased effect, with the first two being the most popular in HMD and SFU and the third one the most commonly used in NT. In terms of the potentially disturbing elements present in the series in question, weakening and dilution of humorous references to taboo subjects such as sexuality, death, drug abuse and religion were noticed, although the criteria for manipulation did not always appear to be consistent. In all these cases, considerable humour loss was observed, with possible consequences on audience appreciation.

Generally speaking, the dubbed versions appear to be more normalized and less of an "emotional rollercoaster" for viewers than their English language counterparts. In particular, the translational choices exemplified above create a less significant gap not only between the serious scenes and the more light-hearted ones in the series, but also between light-hearted or even humorous lines pronounced by characters in what would normally be considered inappropriate circumstances. The result is that viewers watching the dubbed version are made unaware of these continuous shifts between genres and the product is perceived as a more normalized version that does not do justice to the original. Observations on the interconnection of censorship and self-censorship were also mentioned as an issue difficult to assess without direct access to the people who were involved in the dubbing process and to the guidelines provided by the TV networks. Also, the 
possibility was stressed that further manipulation is performed at the time of the actual dubbing involving actors and dubbing directors, who have been known to alter the lines provided by the translators/adaptors merely on the grounds that "it sounds better this way" (personal communication).

Perhaps one of the most surprising findings of this analysis is the fact that, although some general patterns were noticed, text manipulation in terms of language and contents still seems to present an inconsistent character, even allowing for the slight differences among the three shows in question and for issues concerning technical constraints (Fawcett 2003). This seems to confirm the impression that the choices regarding the manipulation of controversial series during the adaptation process are not subject to general regulations on a national level but, more likely, to arbitrary preferences based perhaps on economic and marketing factors that leave little room to considerations about a respectful treatment of the original product. What there might be room for, though, is some improvement in the way translated programmes are handled by TV networks, especially in terms of scheduling choices that would be more suitable to the actual nature of the shows. For example, shows that in their original countries were aired on cable TV or during late-night slots because of content and language should perhaps be programmed according to similar criteria, instead of being expurgated of all possible supposedly disturbing elements in order to be suitable for airing, for example, on national TV during the primetime slot. Alternatively, different adaptations of the same audiovisual products could be created (for example one for TV and one for the home video market), in which viewers should be informed of the kind of changes, if any, operated on the original version ${ }^{9}$.

As a final note, it should also be pointed out that, although it is reasonable to hypothesize that translators/adaptors are often likely to have little power in the decision making aspect of the adaptation process, it is undeniable that the kind of systematic text manipulation noticed above involves issues regarding ethical and professional integrity issues on the part of translators working in AVT. This remark is all the more relevant since the patterns observed do not pertain to just one film or TV series but appear to be extensive to other TV shows that have apparently suffered the same or a similar fate in the last few years.

\section{Bibliography}

Azzaro, Gabriele (2005). Four Letter Films. Taboo Language in Movies. Roma: Aracne.

Bianchi, Diana (forthcoming). "Taming teen-language. The adaptation of Buffyspeak into Italian". In Delia Chiaro, Christine Heiss, and Chiara Bucaria (eds) Between Text and Image. Updating Research in Screen Translation, proceedings of the conference held in Forlì, Italy, $27^{\text {th }}-29^{\text {th }}$ October 2005.

Bucaria, Chiara (2005). "The Perception of Humour in Dubbing vs Subtitling: The Case of Six Feet Under". ESP Across Cultures 2: 34-46.

Bucaria, Chiara (forthcoming). "Laughing to Death: The Perception of Black Humour in Six Feet Under". In Delia Chiaro and Rachele Antonini (eds) Humour, Language, Culture and Translation. 
Bucaria, Chiara and Chiaro, Delia (forthcoming). "End-User Perception of Screen Translation: the Case of Italian Dubbing". TradTerm, CITRAT, State University of São Paulo.

Chiaro, Delia (2006). "Verbally Expressed Humour on Screen: Reflections on Translation and Reception” The Journal of specialized Translation 6, 198-208.

Fawcett, Peter (2003). “The Manipulation of Language and Culture in Film Translation”. In María Calzada Pérez (ed) Apropos of Ideology. Translation Studies on Ideology - Ideologies in Translation Studies. Manchester: St. Jerome, 145-163.

Grieveson, Lee (2004). Policing Cinema. Movies and Censorship in Early-Twentieth-Century America. Berkeley/Los Angeles: University of California Press.

Jansen, Peter (ed.) (1995). Translation and the Manipulation of Discourse. Leuven: CETRA, the Leuven Research Center for Translation, Communication and Cultures.

Magloff, Lisa (2000). "City Guide: Cut! Firing the In-Flight Censor." The International Herald Tribune, 2 June. http://www.iht.com/articles/2000/06/02/trinter.t.php. (last visited on 20 June 2007).

Mathews, Tom Dewe (1994). Censored. The Story of Film Censorship in Britain. London: Chatto and Windus.

Pavesi, Maria and Malinverno, Annalisa (2000). "Sul turpiloquio nella traduzione filmica”. In C. Taylor (ed.). Tradurre il cinema. Trieste: La Stea. 75-90.

Pérez, María Calzada (ed.) (2003). Apropos of Ideology. Translation Studies on Ideology Ideologies in Translation Studies. Manchester: St. Jerome Publishing.

Rundle, Christopher (1999). "Publishing Translations in Mussolini's Italy: A case study of Arnoldo Mondadori". In Susan Bassnett, Rosa Maria Bollettieri Bosinelli and Margherita Ulrych (eds) Textus. English Studies in Italy, XII(2), 427-442.

Rundle, Christopher (2000). "The Censorship of Translation in Fascist Italy". The Translator 6(1), 67-86.

Sturge, Kate (1999). “A Danger and a Veiled Attack. Translating into Nazi Germany”. In Jean Boase-Beier and Michael Holman (eds) The Practices of Literary Translation. Constraints and Creativity. Manchester: St Jerome, 135-146.

Sturge, Kate (2002). Censorship of Translated Fiction in Nazi Germany', In Denise Merkle (ed) TTR: Études sur le texte et ses transformations, Special Issue: Censorship and Translation in the Modern World XV, 153-169

Vandaele, Jeroen (2002). "Funny Fictions: Francoist Translation Censorship of Two Billy Wilder Films". The Translator 8(2), 267-302.

\section{Filmography:}

House, MD (2004 - present)

USA, Fox Broadcasting

Created by David Shore

ITALIAN DUBBED VERSION:

Dr. House - Medical Division

Dubbing performed by VIDEO SOUND SERVICE

Italian dialogues by Adelisa Pitti Leoni, Anna Rita Pasanisi, Emanuela Petrolati, Paolo Turco, Roberta Pelliccioni.

Dubbing directors: Marco Mete, Roberto Del Giudice, Isabella Pasanisi, Anna Rita Pasanisi

Nip/Tuck (2003 - present)

USA, FX Networks

Directed by Ryan Murphy

ITALIAN DUBBED VERSION:

Nip/Tuck

Dubbing performed by VIDEODELTA - Telecittà (TO)

Italian dialogues by Elena Pollacino, Anna Lana.

Dubbing director: Mario Brusa

Six Feet Under (2001-2005)

USA, HBO

Directed by Alan Ball

ITALIAN DUBBED VERSION: 
Six Feet Under

Dubbing performed by EDIT

Italian dialogues by Luca Intoppa, Antonella Damigelli.

Dubbing director: Fabrizio Temperini.

South Park (1997 - present)

USA, Comedy Central

Directed by Trey Parker and Matt Stone

ITALIAN DUBBED VERSION:

South Park

Dubbing performed by SEFIT-CDC

Translated by Elena Di Carlo

Italian dialogues by Marco Mete, Fabrizio Manfredi

Dubbing directors: Marco Mete, Renato Mori, Fabrizio Manfredi

The Nanny (1993-1999)

USA, CBS

Directed by Fran Drescher and Peter Marc Jacobson

ITALIAN DUBBED VERSION:

La Tata

Dubbing performed by STUDIOIMMAGINE

Italian dialogues by Guido Leoni and Massimo Corizza

Dubbing Directors: Guido Leoni, Massimo Corizza and Lorenza Biella

Will \& Grace (1998-1996)

USA, NBC

Directed by David Kohan and Max Mutchnick

ITALIAN DUBBED VERSION:

Will \& Grace

Dubbing performed by MULTIMEDIA NETWORK

Italian dialogues by Daniela Mazzarotta

Dubbing directors: Mario Cordova, Enzo Bruno, Nicola Bruno

Buffy - The Vampire Slayer (1997-2003)

USA, The WB and UPN

Directed by Joss Whedon

ITALIAN DUBBED VERSION:

Buffy

Dubbing performed by PUMAISdue

Italian dialogues by Carlo Dell'Ongaro, Deddi Savagnone,Silvia Gavarotti, Simona esposito, Luciano Roffi, Edoardo Salerno, Fabrizio Pucci, Francesco Chillemi, Eugenio Marinelli

Dubbing directors: FABRIZIO PUCCI, GIUPPY IZZO

Roseanne (1988-1997)

USA, ABC

Directed by Matt Williams

ITALIAN DUBBED VERSION:

Pappa e Ciccia

Dubbing performed by TECNOSOUND

Italian Dialogues by Toni Biocca, Clelia Castaldo, Antonella Damigelli, PAola Giannetti, Antonella Giannini, Luciana Occhipinti, Raffaella Pepitoni, Silvia Pepitoni, Margherita Sestito, Gian Pietro Tomasini

Dubbing director: Emanuela Zanetti

1 For reflections on ideology and translation in general see for example Jansen (1995) and María Calzada Pérez (2003).

2 The practice by which films are edited for different audiences is attested by the presence of numerous online fan forums on this topic. In-flight movies are also often edited for any reference 
to plane crashes, hijacking, etc., as noted, among others, in Magloff 2000, even before the 9/11 attacks.

3 Typically, the fans that have access to the original version are the first ones to notice the discrepancies and to denounce this on blogs and forums, where separate sections dedicated to cuts and censorship in a given series are often present. The same trend is also often noticed in the Italian versions of Japanese anime.

4 The choice of focusing on American series was due to the fact that they were distributed on DVD and hence more readily accessible for analysis, whereas many equally significant British series, e.g. Bodies and Shameless, were only broadcast on satellite TV.

5 For observations on a definition of black/dark humour and related terms see Bucaria 2005 and forthcoming.

6 The classification of films used in Italy includes the labels "film per tutti", "vietato ai minori di 14 anni" and "film vietato ai minori di 18." This is normally applied to DVDs for the home video market as well.

${ }^{7}$ For a recent classification of swearwords in films see Azzaro 2005, whereas observations on the filmic adaptation of strong language from English into Italian are present in Pavesi and Malinverno (2000).

${ }^{8}$ See for example the website "House MD Website" (www.house-md.info, last visited on 3 December 2007)

9 The significance of radically different translation choices in the case of series containing controversial language and themes was recently shown in a study on the dubbed and subtitled versions of SFU (Bucaria 2005), which indicated that these choices might affect audience appreciation of some scenes. 